Check for updates

Cite this: RSC Adv., 2017, 7, 54980

Received 6th October 2017

Accepted 27th November 2017

DOI: $10.1039 / \mathrm{c} 7 \mathrm{ra11019g}$

rsc.li/rsc-advances

\section{Synthesis and characterization of $\mathrm{Gd}_{2} \mathrm{Zr}_{2} \mathrm{O}_{7}$ defect- fluorite oxide nanoparticles via a homogeneous precipitation-solvothermal method}

\author{
Zhe Tang, ${ }^{\text {ab }}$ Zhangyi Huang, ${ }^{\text {ac }}$ Jianqi Qi, (D) *ac Xiaofeng Guo, (D) de Wei Han, ${ }^{\text {ab }}$ \\ Mao Zhou, ab Shuting Peng a and Tiecheng Lu*abc
}

\begin{abstract}
Defect-fluorite structured $\mathrm{Gd}_{2} \mathrm{Zr}_{2} \mathrm{O}_{7}$ nanoparticles were successfully synthesized via a homogeneous precipitation-solvothermal method using urea as a precipitant. The obtained nanoparticles were characterized by X-ray diffraction (XRD), Fourier transform infrared spectroscopy (FT-IR), scanning electron microscopy (SEM), Brunauer-Emmett-Teller (BET) analysis and transmission electron microscopy (TEM). Compared to the traditional solvothermal method, this homogeneous precipitationsolvothermal method has the advantage of producing nanoparticles with small grain sizes, a narrow sizedistribution, high surface areas and little agglomeration. Particularly, the mean crystallite size of $\mathrm{Gd}_{2} \mathrm{Zr}_{2} \mathrm{O}_{7}$ obtained by this method is $20-30 \mathrm{~nm}$, providing a great opportunity of using these nanoparticles as starting nano-sized building blocks for low temperature preparation of homogeneous and dense ceramics.
\end{abstract}

\section{Introduction}

$\mathrm{Gd}_{2} \mathrm{Zr}_{2} \mathrm{O}_{7}$ is one of the most important rare-earth-stabilized zirconia (RESZ) materials due to its potential application as a ceramic waste matrix for immobilizing actinides and fission products. $^{\mathbf{1 , 2}}$ This crystalline system has a general formula $\mathrm{A}_{2} \mathrm{~B}_{2} \mathrm{O}_{7}$, with one eight-coordinated A site (16c) and one sixcoordinated $\mathrm{B}$ site $(16 d)$ that are capable of incorporating a large amount of radionuclides (e.g. $\mathrm{Pu}, \mathrm{U}, \mathrm{Np}, \mathrm{Hf}, \mathrm{Th}, \mathrm{Am}$ and $\mathrm{Cm}) .{ }^{3}$ Previous studies show that $\mathrm{Gd}_{2} \mathrm{Zr}_{2} \mathrm{O}_{7}$ has a high thermal stability, high chemical resistance and durability, ${ }^{4-7}$ which suggests that it can serve as a stable, robust and long-lived waste host. In addition, due to the good mechanical properties (strength and hardness), thermodynamic stability and leaching durability, $\mathrm{Gd}_{2} \mathrm{Zr}_{2} \mathrm{O}_{7}$ also finds versatile applications in many fields, such as thermal barrier coatings, solid electrolytes in solid oxide fuel cells, transparent ceramics, photoactive materials, etc. ${ }^{8-11}$

Controls of sizes and morphologies of grains can greatly affect the physical and chemicals properties of material in related to its applications. Due to the significant advantages in

${ }^{a}$ College of Physical Science and Technology, Sichuan University, Chengdu 610064, P. R. China.E-mail: qijianqi@scu.edu.cn; lutiecheng@scu.edu.cn

${ }^{b}$ Key Laboratory of High Energy Density Physics of Ministry of Education, Sichuan University, Chengdu 610064, Sichuan, P. R. China

'Key Laboratory of Radiation Physics and Technology of Ministry of Education, Sichuan University, Chengdu 610064, Sichuan, P. R. China

${ }^{d}$ Department of Chemistry, Washington State University, Pullman, Washington 99163, USA

${ }^{e}$ The Alexandra Navrotsky Institute for Experimental Thermodynamics, Washington State University, Pullman, Washington 99163, USA small grain sizes, nanostructured materials have been reported to display enhanced or discrepant properties comparing to coarse-grained counterparts. ${ }^{\mathbf{1 2 - 1 4}}$ Previous studies on RESZ show that compared to the conventionally synthesized microcrystalline structures, nanosized ceramics show enhanced radiation resistance, decreased thermal conductivity and increased conductivity. ${ }^{15-19}$ So far, there are reports on using wet chemistry methods, the sol-gel processing, ${ }^{5}$ the gel combustion processing, ${ }^{20}$ the co-precipitation method, ${ }^{21}$ the hydrothermal method ${ }^{22}$ and others, ${ }^{6}$ to prepare $\mathrm{Gd}_{2} \mathrm{Zr}_{2} \mathrm{O}_{7}$ nanoparticles with different chemical homogeneity and phase assemblage. However, those former methods cannot produce nanoparticles with wellcontrolled grain sizes due to the agglomeration as a result of $\mathrm{pH}$ variation.

Thus, in this paper, we introduced a facile homogeneoussolvothermal precipitation method to synthesize wellcrystallized and dispersed $\mathrm{Gd}_{2} \mathrm{Zr}_{2} \mathrm{O}_{7}$ nanoparticles with grain sizes of 20-30 nm. We demonstrated that this method has a better control of the grain size distribution through $\mathrm{pH}$ variation by adjusting the molar ratio of urea. In addition, it provides a more efficient way to synthesis well-dispersed nanoparticles than other wet chemistry routes.

\section{Experimental section}

In the synthesis experiment, $\mathrm{Gd}\left(\mathrm{NO}_{3}\right)_{3} \cdot 6 \mathrm{H}_{2} \mathrm{O}(>99.99 \%$, Ruike $\mathrm{RE}$, China), $\mathrm{ZrOCl}_{2} \cdot 8 \mathrm{H}_{2} \mathrm{O}(>99.99 \%$, Aladdin) were mixed with a stoichiometric ratio of $1: 1$ and dissolved in deionized water. Ethanol and different amounts of urea were added to the mixed solution while it was constantly stirring. After a fully mixing, the solution was heated at $200{ }^{\circ} \mathrm{C}$ for $24 \mathrm{~h}$ in a Teflon beaker and 


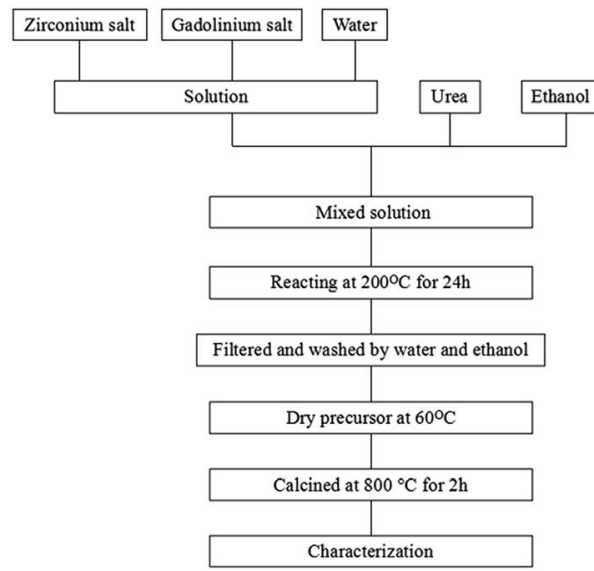

Fig. 1 The scheme of the synthesis route.

a precipitate was yielded. The precipitate was then filtered and washed with deionized water and ethanol in turns for several times. The reactants diluted by ethanol were dried at $60{ }^{\circ} \mathrm{C}$. Finally, the dry precursors were calcined at $800{ }^{\circ} \mathrm{C}$ for $2 \mathrm{~h}$. The synthesis scheme is shown in Fig. 1. We compared our synthetic samples by the homogeneous precipitation-solvothermal method with those obtained by the co-precipitation method. In the co-precipitation method, the dilute ammonium hydroxide was used as the precipitant, which was mixed with the solution containing $\mathrm{Gd}^{3+}$ and $\mathrm{Zr}^{4+}$. After stirring the solution for $60 \mathrm{~min}$ and aging for $24 \mathrm{~h}$, the formed gel-like precipitate was obtained from the solution through the centrifugal separation. Then the precipitate was washed with deionized water and ethanol for several times and dried at $60{ }^{\circ} \mathrm{C} . \mathrm{Gd}_{2} \mathrm{Zr}_{2} \mathrm{O}_{7}$ powders were finally synthesized after a calcination at $800{ }^{\circ} \mathrm{C}$ for $2 \mathrm{~h}$.

The synthetic products were characterized by X-ray diffraction (XRD), Scanning electron microscope (SEM), transmission electron microscopy (TEM), Infrared spectroscopy (IR), and Brunauer-Emmett-Teller (BET) surface area measurements. The quantitative phase analysis was derived from the refinement of the XRD patterns using MAUD Rietveld program.

\section{Results and discussion}

The XRD patterns (Fig. 2) of $\mathrm{Gd}_{2} \mathrm{Zr}_{2} \mathrm{O}_{7}$ synthesized by the homogeneous-solvothermal precipitation method suggest a good crystallinity. Particularly, when the molar ratio of urea $: \mathrm{Gd}^{3+}: \mathrm{Zr}^{4+}$ is $30: 1: 1$, the phase is completely crystallized in the defect-fluorite structure, evidenced by the strong and sharp peaks resulting from the (111), (200), (220), (311) and (222) reflections. By using the Scherrer equation implemented by JADE 6, we performed a pattern profile fitting that determined the average crystallite size to be $7.0 \pm 0.3 \mathrm{~nm}$ which is similar to that reported by Popov et al. $(\sim 10 \mathrm{~nm}){ }^{23,24}$ Because of our powders were well crystallized in small sizes, we can control the particle size by applying different calcination temperatures to the preliminary particles. Furthermore, the XRD patterns suggest that the molar ratio of urea: $\mathrm{Gd}^{3+}: \mathrm{Zr}^{4+}$ has an

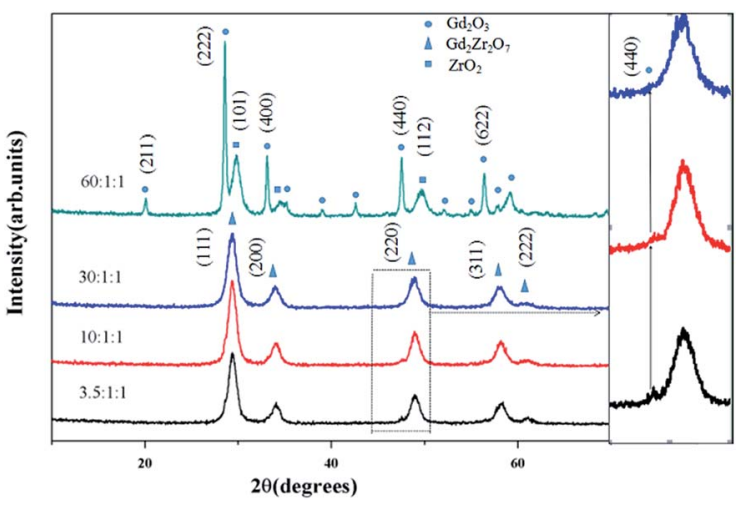

Fig. 2 XRD patterns of the calcined powders with different concentrations of urea.

influence on the formation of the final products (Fig. 2). At a lower concentrated level of urea, we observed a weak peak attributed to the (440) reflection of $\mathrm{Gd}_{2} \mathrm{O}_{3}$, which was not shown in the product when the urea molar ratio is 30 . Though at a very high urea concentration (molar ratio of 60), the XRD pattern shows no formation of $\mathrm{Gd}_{2} \mathrm{Zr}_{2} \mathrm{O}_{7}$ but $\mathrm{Gd}_{2} \mathrm{O}_{3}$ and $\mathrm{ZrO}_{2}$ instead (Fig. 3).

The relationship between the urea concentration and the final product can be explained by the $\mathrm{pH}$ variation. When the temperature of mixed solution increases, the hydrolysis reaction takes place and provides hydroxide ions described in eqn (1) and (2),

$$
\begin{gathered}
\mathrm{CO}\left(\mathrm{NH}_{2}\right)_{2}+\mathrm{H}_{2} \mathrm{O}=\mathrm{CO}_{2}+2 \mathrm{NH}_{3} \\
\mathrm{NH}_{3}+\mathrm{H}_{2} \mathrm{O}=\mathrm{NH}_{3}{ }^{4+}+\mathrm{OH}^{-}
\end{gathered}
$$

The hydrolysis reaction in the solution can constantly provide hydroxide ions with which $\mathrm{Gd}^{3+}$ and $\mathrm{Zr}^{4+}$ are combined, so that the mixing of $\mathrm{Gd}$ and $\mathrm{Zr}$ happens in a molecular level which is the basis for synthesizing homogeneous $\mathrm{Gd}_{2} \mathrm{Zr}_{2} \mathrm{O}_{7}$ nanocrystals. Thus, the concentration of hydroxide ions is critical as it can determine the phases formed in the final products. If the concentration of urea is low, the concentration of hydroxide ions is also low and not enough for $\mathrm{OH}^{-}$to be

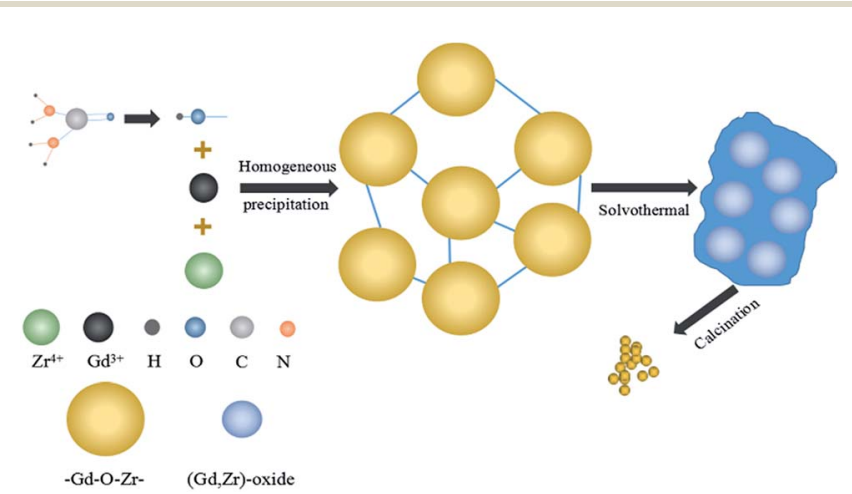

Fig. 3 Schematic diagram illustrating the formation and structural evolution of $\mathrm{Gd}_{2} \mathrm{Zr}_{2} \mathrm{O}_{7}$ nanocrystalline powders. 
reacted with $\mathrm{Gd}^{3+}$ and $\mathrm{Zr}^{4+}$. In addition, though theoretically urea could provide enough hydroxide ions for reactions with $\mathrm{Gd}^{3+}$ and $\mathrm{Zr}^{4+}$, the hydrolysis reactions described in eqn (1) and (2) are in dynamic equilibrium in a hermetic reactor, which could result in an insufficient concentration of hydroxide ions. For instance, no precipitate is formed when the molar ratio of urea : $\mathrm{Gd}^{3+}: \mathrm{Zr}^{4+}$ is lower than $2: 1: 1$. As the concentration of urea increased, the content of hydroxide ions is also increased as seen from eqn (1) and (2). After the molar ratio of urea reaches 3.5, the solution contains enough hydroxide ions to be combined with $\mathrm{Gd}^{3+}$ and $\mathrm{Zr}^{4+}$ (Fig. 2) that yielded phases consist of a defect-fluorite phase $\mathrm{Gd}_{2} \mathrm{Zr}_{2} \mathrm{O}_{7}$ as the main phase with a tiny amount of $\mathrm{Gd}_{2} \mathrm{O}_{3}$ as a secondary phase. We found out that the amount of the impurity $\left(\mathrm{Gd}_{2} \mathrm{O}_{3}\right)$ decreases as the mole ratio of urea increases up to certain values; and at a proper mole rate (30:1:1), we produced pure $\mathrm{Gd}_{2} \mathrm{Zr}_{2} \mathrm{O}_{7}$ in defect-fluorite structure (Fig. 2). However, on the other hand, if the concentration of urea is too high, such as $60: 1: 1$, the hydroxide ions would segregate $\mathrm{Gd}^{3+}$ and $\mathrm{Zr}^{4+}$, and react with them separately to form $\mathrm{Gd}(\mathrm{OH})_{3}$ and $\mathrm{Zr}(\mathrm{OH})_{4}$ instead of (Gd, $\mathrm{Zr}$ ) hydroxide that eventually leads to products as $\mathrm{Gd}_{2} \mathrm{O}_{3}$ and $\mathrm{ZrO}_{2}$ (Fig. 2).

The hydrolysis reactions described by eqn (1) and (2) are known as homogeneous precipitations that produce a homogeneous precipitation of ( $\mathrm{Gd}, \mathrm{Zr}$ ) hydroxide as described in eqn (3). ${ }^{22}$ Then the next step occurred under heating is the solvothermal process, during which the added ethanol can effectively break up the aggregates in the (Gd, Zr)-oxides at $200{ }^{\circ} \mathrm{C}$, and the alkoxyl group can substitute hydroxyl group as described in eqn (4),

$$
\mathrm{ZrOCl}_{2}+\mathrm{Gd}\left(\mathrm{NO}_{3}\right)_{3}+\mathrm{OH}^{-} \rightarrow(\mathrm{Gd}, \mathrm{Zr}) \text {-hydroxide }
$$

(Gd, $\mathrm{Zr}$ )-hydroxide $+\mathrm{ROH} \rightarrow \mathrm{Gd}_{2} \mathrm{Zr}_{2} \mathrm{O}_{7}$ nanocrystal $+m \mathrm{H}_{2} \mathrm{O}$

In this homogeneous precipitation-solvothermal method, the solvothermal process is the key step for synthesizing pure defect-fluorite phase $\mathrm{Gd}_{2} \mathrm{Zr}_{2} \mathrm{O}_{7}$ nanocrystals. As a comparison, we performed a co-precipitation synthesis without the

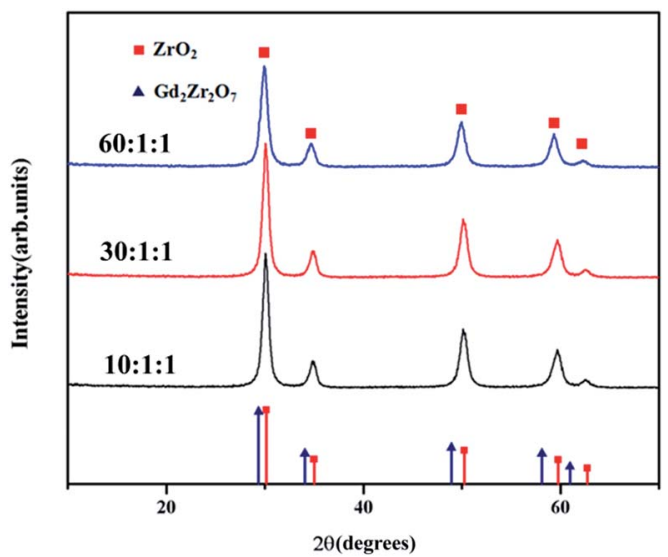

Fig. 4 XRD patterns of calcined powders without the solvothermal process. solvothermal process. The mixed solution resulted from the homogeneous precipitation was heated in a thermostatted oil bath that maintained at $120{ }^{\circ} \mathrm{C}$ for $2 \mathrm{~h}$ with a constant stirring. Then the suspension was cooled and the white precipitate was washed multiple times with deionized water and ethanol. Then the precursors were dried in vacuum at $60^{\circ} \mathrm{C}$ and then calcined at $800{ }^{\circ} \mathrm{C}$ for $2 \mathrm{~h}$. The XRD patterns of the products are given in Fig. 4. It's clear that without a solvothermal process, the synthesized powder is pure $\mathrm{ZrO}_{2}$. Numbers of studies show both $\mathrm{A}_{2} \mathrm{~B}_{2} \mathrm{O}_{7}$ oxides and rare earth oxides can be synthesized by homogeneous precipitation method using urea as precipitant. ${ }^{25,26}$ Nevertheless, due to the low-temperature calcination, using only homogeneous precipitation method could lead to $\mathrm{A}_{2} \mathrm{~B}_{2} \mathrm{O}_{7}$ oxides mixed with $\mathrm{BO}_{2}$ crystalline phases and perhaps poor crystallized $\mathrm{AO}_{2}$ or A-containing polymers, partly due to the closed formation enthalpies of these phases at $800{ }^{\circ} \mathrm{C}$. Similar phenomena were observed in other complex oxide systems, such as garnet. ${ }^{27,28}$ During the solvothermal process, $\mathrm{Gd}_{2} \mathrm{Zr}_{2} \mathrm{O}_{7}$ was formed because of more $\mathrm{OH}^{-}$was produced by the hydrolysis of urea with the aids of high temperature and high pressure. Compared with $\mathrm{Gd}^{3+}, \mathrm{Zr}^{4+}$ can be precipitated at lower $\mathrm{pH}$ value. With the absence of solvothermal process, only $\mathrm{Zr}^{4+}$, rather than $\mathrm{Gd}^{3+}$, was precipitated because of the relatively low $\mathrm{pH}$ value provided by the insufficient hydrolysis of urea, giving rise to the formation of the precursor of $\mathrm{ZrO}_{2}$. Thus, our homogeneous precipitation-solvothermal method was proved to be a new feasible route for synthesizing pure phase $\mathrm{Gd}_{2} \mathrm{Zr}_{2} \mathrm{O}_{7}$ as a base for various functional nanomaterials.
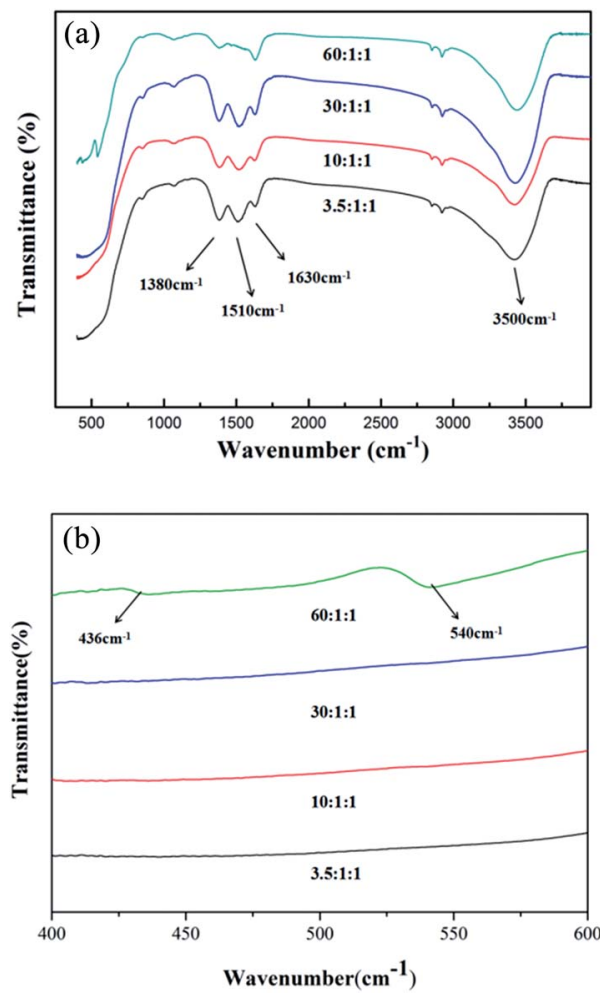

Fig. 5 IR absorption spectra of calcined powders with different concentrations of urea (a) wavenumber between $400 \mathrm{~cm}^{-1}$ and $4000 \mathrm{~cm}^{-1}$; (b) wavenumber between $400 \mathrm{~cm}^{-1}$ and $600 \mathrm{~cm}^{-1}$. 


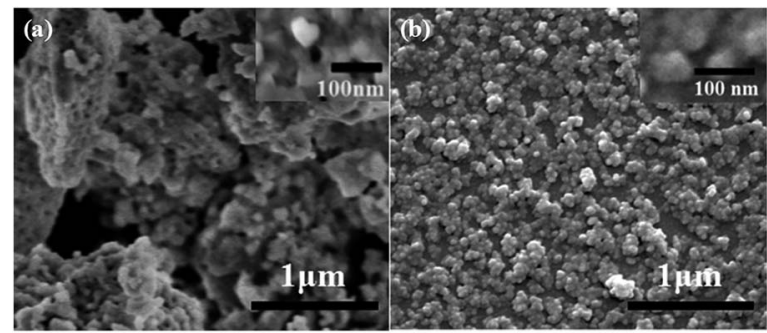

Fig. 6 SEM of powders synthesized by (a) the co-precipitation method; (b) the homogeneous precipitation-solvothermal method.

IR absorption spectra are used to determine the site preferences of $\mathrm{Gd}$ and $\mathrm{Zr}$ in $\mathrm{Gd}_{2} \mathrm{Zr}_{2} \mathrm{O}_{7}$ as it is sensitivity to the change of the local structure resulting from distortion of polyhedra and element substitutions. The IR spectra of samples prepared by the homogeneous precipitation-solvothermal method with different concentrations of urea are presented in Fig. 5. According to former studies, the infrared spectra of $\mathrm{A}_{2} \mathrm{~B}_{2} \mathrm{O}_{7}$ compounds contain seven IR-active optic modes. ${ }^{29,30}$ Fig. 5(a) shows the IR absorption spectra of powders with different concentrations of urea in the wave range of $400 \mathrm{~cm}^{-1}$ to $4000 \mathrm{~cm}^{-1}$. There are several characteristic absorption bands at about $436 \mathrm{~cm}^{-1}, 540 \mathrm{~cm}^{-1}, 1380-1630 \mathrm{~cm}^{-1}$, and $3500 \mathrm{~cm}^{-1}$. It has been known that the appearances of the band centered at approximately the $1380-1630 \mathrm{~cm}^{-1}$ and $3500 \mathrm{~cm}^{-1}$ bands are evidence of the existence of water molecules attached to the powders. In Fig. 5(b), the spectrum of the sample with the mole ratio of urea as 60 shows peaks in the range of $400 \mathrm{~cm}^{-1}$ to $600 \mathrm{~cm}^{-1}$, from which the peak at $540 \mathrm{~cm}^{-1}$ is attributed from $\mathrm{Zr}-\mathrm{O}$ stretching modes, and that at $436 \mathrm{~cm}^{-1}$ is caused by the $\mathrm{O}-$ Gd-O bending modes. These are another evidence besides XRD that show the presence of $\mathrm{Gd}_{2} \mathrm{O}_{3}$ and $\mathrm{ZrO}_{2}$ when the urea is high concentrated during the homogeneous precipitationsolvothermal synthesis.

In order to understand the micro-morphologies and microstructures of synthetic products made by the homogeneous precipitation-solvothermal method as compared to coprecipitation method, we performed SEM on $\mathrm{Gd}_{2} \mathrm{Zr}_{2} \mathrm{O}_{7}$

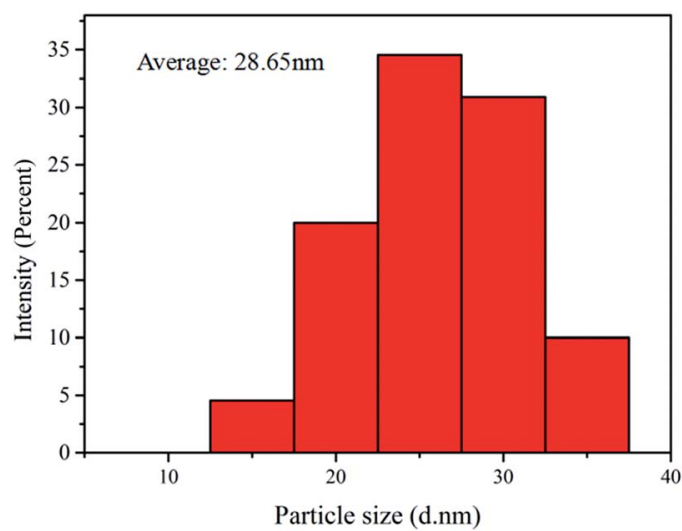

Fig. 7 The particle size distribution of $\mathrm{Gd}_{2} \mathrm{Zr}_{2} \mathrm{O}_{7}$ nanocrystal powders synthesized by the homogeneous precipitation-solvothermal method. powders synthesized by these two methods (Fig. 6). Fig. 6(b) shows large particles of pure defect-fluorite nanocrystalline phase $\mathrm{Gd}_{2} \mathrm{Zr}_{2} \mathrm{O}_{7}$ powders prepared by the homogeneous precipitation-solvothermal method with urea mole ratio as 30 . The morphology suggests well-dispersed and homogeneous features. While in Fig. 6(a), particles prepared by the coprecipitation method show elevated agglomerations that grains are interconnected with each other to form larger microstructures that have irregular morphologies and porous networks. Compared to co-precipitation method, our new method produces $\mathrm{Gd}_{2} \mathrm{Zr}_{2} \mathrm{O}_{7}$ powders with a better dispersity and a low level of aggregation. Furthermore, the particle sizes of samples synthesized by our method estimated by Nano Measurer 1.2 are in a relatively-narrow particle-size distribution within the range of 20-30 $\mathrm{nm}$ with a small mean particle size as $28.7 \pm 0.8 \mathrm{~nm}$ (shown in Fig. 7).

TEM micrographs of our synthetic samples suggest the nature of nanocrystalline as evidenced in Fig. 8. It is concluded by the morphological image (Fig. 8(a)) that $\mathrm{Gd}_{2} \mathrm{Zr}_{2} \mathrm{O}_{7}$ powders are well-dispersed nanoparticles without tight aggregations. The crystal structure is confirmed by selected area diffraction (SAED) to be defect-fluorite shown in Fig. 8(b). The crystallite size determined by HRTEM (Fig. $8(\mathrm{c})$ ) is $\sim 7 \mathrm{~nm}$ in agreement

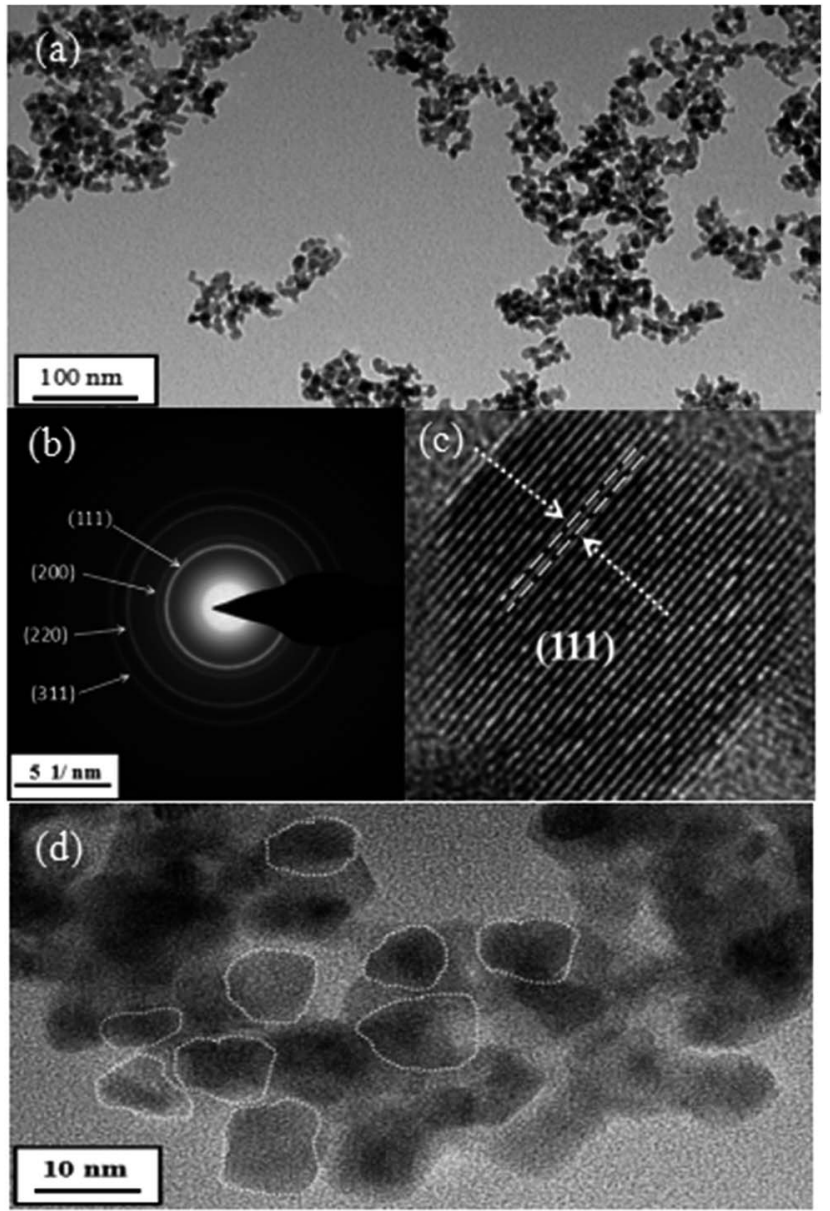

Fig. 8 (a) TEM image of morphology, (b) SAED pattern, (c) and (d) HRTEM images of $\mathrm{Gd}_{2} \mathrm{Zr}_{2} \mathrm{O}_{7}$ powders. 


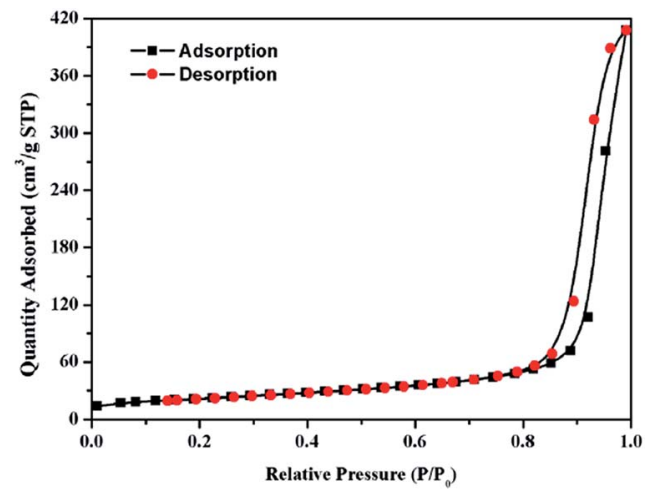

Fig. 9 Nitrogen adsorption-desorption isotherms of $\mathrm{Gd}_{2} \mathrm{Zr}_{2} \mathrm{O}_{7}$ nanocrystalline powders prepared by the homogeneous precipitationsolvothermal method.

with the one by Scherrer formula; and the clear and regular crystal lattice distance indicates that $\mathrm{Gd}_{2} \mathrm{Zr}_{2} \mathrm{O}_{7}$ phases are highly crystalline. Well-dispersed $\mathrm{Gd}_{2} \mathrm{Zr}_{2} \mathrm{O}_{7}$ nanoparticles shown in the Fig. 8(d) HRTEM image have sphere-like or ellipsoid shapes. As mentioned above, this homogeneous precipitation-solvothermal method can be used to synthesize $\mathrm{Gd}_{2} \mathrm{Zr}_{2} \mathrm{O}_{7}$ in smaller particle sizes and with a good dispersity at a relatively low temperature about $200{ }^{\circ} \mathrm{C}$.

The BET surface area and total pore volume of the calcined powder were studied by the gas absorption analysis. The $\mathrm{N}_{2}$ adsorption/desorption isotherms of the powders which produced by the mole ratio of urea, $\mathrm{Gd}^{3+}$ and $\mathrm{Zr}^{4+}$ is $30: 1: 1$ are shown in Fig. 9. The $\mathrm{Gd}_{2} \mathrm{Zr}_{2} \mathrm{O}_{7}$ powders prepared via homogeneous precipitation-solvothermal processing displays a type H3 hysteresis loop (according to the IUPAC classification scheme), indicating smaller particle sizes and a good dispersity. The specific surface area of the pure defect-fluorite phase $\mathrm{Gd}_{2} \mathrm{Zr}_{2} \mathrm{O}_{7}$ powder is $76.9 \mathrm{~m}^{2} \mathrm{~g}^{-1}$, and the total pore volume is about 0.63 $\mathrm{m}^{2} \mathrm{~g}^{-1}$, and with an average pore radius of $26.04 \mathrm{~nm}$, which further proves our conclusion compared with the SEM result. Thus, we can conclude that via the homogeneous precipitationsolvothermal method, $\mathrm{Gd}_{2} \mathrm{Zr}_{2} \mathrm{O}_{7}$ nanoparticles are well dispersed and the particle sizes are small.

\section{Conclusions}

In summary, well-crystalized and well-dispersed defect-fluorite phase $\mathrm{Gd}_{2} \mathrm{Zr}_{2} \mathrm{O}_{7}$ nanocrystalline powders have been successfully synthesized by the homogeneous precipitationsolvothermal method. The reactions of precipitation and crystallization both occur at a relatively low temperature so that the high-temperature calcination can be eliminated. We discovered that under the appropriate mole ratio of urea : $\mathrm{Gd}^{3+}: \mathrm{Zr}^{4+}$ as $30: 1: 1$, the formed $\mathrm{Gd}_{2} \mathrm{Zr}_{2} \mathrm{O}_{7}$ nanocrystalline powder is most sphere-like (with some oval shape) and has a narrow particle distribution with an average diameter of 20-30 nm. This research provides a new facile and efficient route to prepare $\mathrm{Gd}_{2} \mathrm{Zr}_{2} \mathrm{O}_{7}$ nanocrystals at a lower temperature with shortened reaction time, which can also be extended to the synthesis of
$\mathrm{Gd}_{2} \mathrm{Zr}_{2} \mathrm{O}_{7}$-based functional nanomaterials and other fluoriteoxide nanocrystals (like $\mathrm{La}_{2} \mathrm{Zr}_{2} \mathrm{O}_{7}$ ).

\section{Conflicts of interest}

There are no conflicts to declare.

\section{Acknowledgements}

This work was supported by the National Natural Science Foundation of China under Grant No. 11505122 and Grant No. 91326103, the ITER Program (No. 2014GB125002).

\section{References}

1 A. Gomez-Perez, J. Prado-Gonjal, D. Munoz-Gil, A. AndradaChacon, J. Sanchez-Benitez, E. Moran, M. T. Azcondo, U. Amador and R. Schmidt, RSC Adv., 2015, 5, 85229-85241.

2 M. K. Patel, V. Vijayakumar, S. Kailas, D. K. Avasthi, J. C. Pivin and A. K. Tyagi, J. Nucl. Mater., 2008, 380, 93-98. 3 L. Wang, X. Y. Shu, X. R. Lu, Y. L. Wu, Y. Ding and S. Zhang, Mater. Lett., 2017, 196, 403-405.

4 M. Lang, F. X. Zhang, J. M. Zhang, J. W. Wang, B. Schuster, C. Trautmann, R. Neumann, U. Becker and R. C. Ewing, Nat. Mater., 2009, 8, 793-797.

5 J. Shamblin, M. Feygenson, J. Neuefeind, C. L. Tracy, F. X. Zhang, S. Finkeldei, D. Bosbach, H. D. Zhou, R. C. Ewing and M. Lang, Nat. Mater., 2016, 15, 507.

6 X. R. Lu, Y. Ding, X. Y. Shu, X. L. Mao and X. L. Wang, RSC $A d v .$, 2015, 5, 64247-64253.

7 A. Navrotsky, T. Shvareva and X. Guo, in Uranium - Cradle to Grave, ed. P. C. Burns and G. E. Sigmon, Mineralogical Association of Canada, Winnipeg, MB, Cananda, 2013, vol. Short Course, ch. 5, pp. 147-164.

8 Z. G. Liu, J. H. Ouyang, Y. Zhou and X. L. Xia, Mater. Lett., 2008, 62, 4455-4457.

9 Z. G. Liu, J. H. Ouyang, Y. Zhou and X. L. Xia, J. Alloys Compd., 2010, 490, 277-281.

10 Z. J. Wang, G. H. Zhou, X. P. Qin, Y. Yang, G. J. Zhang, Y. Menke and S. W. Wang, J. Alloys Compd., 2014, 585, 497-502.

11 M. S. Rabasovic, D. Sevic, J. Krizan, M. Terzic, J. Mozina, B. P. Marinkovic, S. Savic-Sevic, M. Mitric, M. D. Rabasovic and N. Romcevic, J. Alloys Compd., 2015, 622, 292-295.

12 M. G. Bellino, D. G. Lamas and N. E. W. de Reca, Adv. Funct. Mater., 2006, 16, 107-113.

13 G. Xu, Y. W. Zhang, C. S. Liao and C. H. Yan, Phys. Chem. Chem. Phys., 2004, 6, 5410-5418.

14 C. W. Nan, A. Tschope, S. Holten, H. Kliem and R. Birringer, J. Appl. Phys., 1999, 85, 7735-7740.

15 S. K. Gupta, P. S. Ghosh, C. Reghukumar, N. Pathak and R. M. Kadam, RSC Adv., 2016, 6, 44908-44920.

16 J. M. Zhang, J. Lian, A. F. Fuentes, F. X. Zhang, M. Lang, F. Y. Lu and R. C. Ewing, Appl. Phys. Lett., 2009, 94, 243110.

17 S. Dey, J. W. Drazin, Y. Q. Wang, J. A. Valdez, T. G. Holesinger, B. P. Uberuaga and R. H. R. Castro, Sci. Rep., 2015, 5, 7746. 
18 G. Soyez, J. A. Eastman, L. J. Thompson, G. R. Bai, P. M. Baldo, A. W. McCormick, R. J. DiMelfi, A. A. Elmustafa, M. F. Tambwe and D. S. Stone, Appl. Phys. Lett., 2000, 77, 1155-1157.

19 Y. W. Zhang, S. Jin, Y. Yang, G. B. Li, S. J. Tian, J. T. Jia, C. S. Liao and C. H. Yan, Appl. Phys. Lett., 2000, 77, 34093411.

20 B. P. Mandal, A. Banerji, V. Sathe, S. K. Deb and A. K. Tyagi, J. Solid State Chem., 2007, 180, 2643-2648.

21 Z. Y. Huang, J. Q. Qi, L. Zhou, Z. Feng, X. H. Yu, Y. C. Gong, M. Yang, Q. W. Shi, N. Wei and T. C. Lu, J. Appl. Phys., 2015, 118, 214901.

22 Y. W. Zhang, G. Xu, Z. G. Yan, Y. Yang, C. S. Liao and C. H. Yan, J. Mater. Chem., 2002, 12, 970-977.

23 V. V. Popov, V. F. Petrunin, S. A. Korovin, A. P. Menushenkov, O. V. Kashurnikova, R. V. Chernikov, A. A. Yaroslavtsev and Y. V. Zubavichus, Russ. J. Inorg. Chem., 2011, 56, 1538-1544.
24 V. V. Popov, Y. V. Zubavichus, A. P. Menushenkov, A. A. Yaroslavtsev, E. S. Kulik, V. F. Petrunin, S. A. Korovin and N. N. Trofimova, Russ. J. Inorg. Chem., 2014, 59, 279-285.

25 H. S. Xue, W. N. Zhang, X. Y. Li, X. C. You, J. S. Rao and F. S. Pan, Electron. Mater. Lett., 2017, 13, 255-259.

26 R. Gunawidjaja, T. Myint and H. Eilers, J. Phys. Chem. C, 2013, 117, 14427-14434.

27 X. Guo, A. H. Tavakoli, S. Sutton, R. K. Kukkadapu, L. Qi, A. Lanzirotti, M. Newville, M. Asta and A. Navrotsky, Chem. Mater., 2014, 26, 1133-1143.

28 X. Guo, A. Navrotsky, R. K. Kukkadapu, M. H. Engelhard, A. Lanzirotti, M. Newville, E. S. Ilton, S. Sutton and H. Xu, Geochim. Cosmochim. Acta, 2016, 189, 269-281.

29 L. Zhou, Z. Y. Huang, J. Q. Qi, Z. Feng, D. X. Wu, W. Zhang, X. H. Yu, Y. B. Guan, X. T. Chen, L. D. Xie, K. Sun and T. C. Lu, Metall. Mater. Trans. A, 2016, 47, 623-630.

30 M. A. Subramanian, G. Aravamudan and G. V. S. Rao, Prog. Solid State Chem., 1983, 15, 55-143. 